\title{
Development of promiscous rhizobia for diverse rabi legumes (Chickpea, Pea and Lentil)
}

\author{
Ikbal $^{1 *}$, Mukesh R. Jangra ${ }^{1}$, K. M. Sarim ${ }^{2}$ and V.K. sikka ${ }^{1}$ \\ ${ }^{1}$ Department of Biotechnology and Molecular Biology, CCS Haryana Agricultural University, Hisar-125004 \\ (Haryana), INDIA \\ ${ }^{2}$ Department of Microbiology, CCS Haryana Agricultural University, Hisar-125004 (Haryana), INDIA \\ *Corresponding author. E-mail: iqbalshah5330@gmail.com
}

Received: June 12, 2016; Revised received:December 1, 2016; Accepted: January 21, 2017

\begin{abstract}
Conjugation between microsymbiont was used to create genetic variations in rhizobia for diverse rabi legumes (chickpea, pea and lentil) with better characteristics in nodulation and nitrogen fixation process. Ten antibiotics were used as selectable markers for the screening of twenty four bacterial strains to be used in mating experiments for obtaining transconjugants. All bacterial strains were sensitive to gentamycin and resistant to streptomycin, kanamycin and sulphanilamide. Total five fusants were obtained from each rhizobial cross combination with the help of electro-poration. Modified transconjugants, rhizobial strains had promiscuous infection with 50-122\% more nodules showed significant increase in shoot fresh weight, dry weight and total nitrogen content in chickpea, pea and lentil plants. Electrofusants rhizobial strains improved shoot nitrogen content up to $67 \%$ in lentil and $54 \%$ in pea and chickpea plants. The amount of nitrogen fixed in chickpea was highest $(3.71 \mathrm{gm})$ by transconjugants DP-C6HLN followed by DP-C6-HP14 (3.56gm). Transconjugants DP-HP14-HLN fixed the highest amount of nitrogen $(3.92 \mathrm{gm})$ in pea and $4.06 \mathrm{gm}$ in lentil plants. Plasmids were also analyzed in order to characterize their role in the evolution of rhizobial symbionts and their involvement in symbiotic behaviour. The developed Rhizobium strains with improved symbiotic association and ability to infect across strict specificity for host legumes would be of great help for the farming community at large.
\end{abstract}

Keywords: Biofertilizer, Nitrogen fixation, Symbiosis, Transconjugants

\section{INTRODUCTION}

Nitrogen $(\mathrm{N})$ is very essential for most biological compounds so it is required for the growth of living organisms (Mosier and Syers, 2004). It is one of the major factors limiting crop yield (Zhao et al., 2005). Therefore nitrogen applied into soil as chemical fertilizer to gain high crop productivity. Most of these applied chemical fertilizers never reach to the roots and contaminate the environment, especially water and soil (Jaynes et al., 2001). To balance the yield of crops and environmental perturbations, efficient use of available resources, like free atmospheric nitrogen, is necessary (Rosenblueth et al., 1998). As a consequence of the persistent energy crises and higher fertilizer costs, Biological Nitrogen Fixation (BNF) has become one of the most attractive strategies for the development of sustainable agricultural systems (Dixon and Kahn, 2004). BNF is an efficient source of $\mathrm{N}_{2}$ that convert nitrogen gas into ammonia through symbiotic association of plants and microorganisms (Shiferaw et al., 2004). Symbiotic interaction between Rhizobium and leguminous plants is very specific. The specificity of the symbiosis depends on a complex series of genes expression in particular rhizobia and its native host
(Carden and Felle, 2003). Beside this recognition signals are not only factor of specificity. The host specificity may vary among the rhizobia (Li et al., 2011). There are indications that the rhizobia infecting legumes in areas outside the host specificity (MartınezRomero and Caballero-Mellado, 1996). Genetic exchange and rearrangement among heterologous Rhizobium spp. leading to broadening of host range (Young and Johnston, 1989; Valassak et al., 1997). Such type of rhizobia having broad host range could be beneficial for the agricultural practices as most of the commercially available strains have a very narrow host range. Thus choosing the correct inoculant group for a particular legume host is difficult for effective nodulation (Esperanza and Monica, 1990). Broadening of host range may be brought by manipulating both rhizobia and plant hosts and by eventually creating an artificial rhizosphere. Electroporation is a novel approach for inducing recombinations in bacterial strains through conjugation (Chassy et al., 1988; Chitchanok et al., 2011). The objective of this study was to improve nodulation and symbiosis with non host leguminous plants through genetic modifications. This approach is used to obtain a cross infective rhizobia. It could prove to be one of the most valuable contributions to the practical 
agriculture. Such promiscuous Rhizobium strains with improved efficiency to fix nitrogen would acts as a single inoculum for all the rabi legumes and may add higher amount of nitrogen per unit area

\section{MATERIALS AND METHODS}

Isolation of bacterial cultures: Two hundred ninety five rhizobia were isolated from nodulated plants (chickpea, pea and lentil) collected from well spread out virgin sites of Bhiwani, Gurgaon and Hisar districts of Haryana state. The sterilized nodules were crushed and the rhizobial cultures were isolated by streak plate methods (Vincent, 1970). Isolates were grown at $28^{\circ} \mathrm{C}$ and preserved in $20 \%$ glycerol at $-80^{\circ} \mathrm{C}$.

Screening of rhizobial isolates: All the wild type rhizobial isolates were analysed for their growth behaviour on five different media containing diverse carbon source viz. mannitol (YEMA), glucose (GSY), minimal salts and glucose, carboxy methyl cellulose (CMC) and pectin (PM). Colony size of each strain was measured and the isolates showing better growth on CMC and pectin medium were selected.

Intrinsic antibiotic resistance pattern: Ten antibiotics Chloramphenicol (Cm), Streptomycin (Str), Tetracycline (Tc), Sulphanilamide (Spn), Ampicilin (Am), Kanamycin (Kn), Erythromycin (Erth), Cephalotaxime (Cef), Gentamycin (Gm) and Rifampicine (Rif) were used in this study with different concentration for genetically marking the different bacterial strains (Table 1). Filter-sterilized aliquots of each antibiotic were added aseptically to sterile YEMA medium at $50^{\circ} \mathrm{C}$ to give the final concentrations. Control plates contained no antibiotic. Intrinsic antibiotic resistance (IAR) of each selected isolate was evaluated according to Eaglesham's technique as described by Hashem et al. (1998). Each isolate was grown in YEMA with different concentrations of antibiotics to late exponential phase. Plates were incubated at $28^{\circ} \mathrm{C}$ for 7 days and the highest concentration where colony's diameter was similar to control assay was recorded as the resistance level. Antibiotic for which the particular strain showing resistance were considered as the selectable marker.

Preparation of electro-competent cells: $300 \mathrm{ml}$ of GSY broth was inoculated with $20 \mathrm{ml}$ of freshly grown cultures separately. These were incubated at $30^{\circ} \mathrm{C}$ under constant shaking conditions for $24 \mathrm{hrs}$ and harvested at early to mid log phase in cooling centrifuge at $10000 \mathrm{rpm}$ for $10 \mathrm{~min}$. Pellets were washed two times with pre-chilled sterile distilled water and then washed with $20 \%$ glycerol two times. Supernatant was discarded by leaving $100 \mu 1$ of it in Oakridge tube. Pellet was gently mixed in it and transferred in micro-centrifuge tube.

Bacterial mating by electro-fusion: Conjugation among pairs of rhizobial isolates was carried out through electro-fusion experiment. Selected rhizobial isolates $(100 \mu 1$ of each) having contrasting antibiotic markers (Table 2) put into electro-poration cuvette. Electric shock of $1000 \mathrm{~V}$ to $2500 \mathrm{~V}$ was applied for 30 milliseconds with the help of electro-cell manipulator, model 600 (BTX Inc.).These zapped cells were grown on complete broth medium for 3 hrs. Representative media were supplemented with appropriate antibiotics for each cross and the transconjugants appeared on selective medium were picked up.

In-gel analysis for plasmid profiling: Plasmid pattern of the bacterial isolates analysed by in gel lysis method. Freshly grown cultures were centrifuged and pallets mixed with $20 \mu \mathrm{l}$ SRL solution. These samples were loaded in the wells of SDS-agarose gel and electrophoresis was carried out initially at low voltage (20V for 15 minutes) and after that at $80 \mathrm{~V}$. The gel was submerged in dilute ethidium bromide $(0.1 \%)$ solution for staining then it was viewed under UV light using UV trans-illuminator.

Plant infection test: Symbiotic infection behaviour and cross infectivity of selected rhizobial isolates and transconjugants were analysed by plant infection test. Seeds of chickpea, pea and lentil were surface sterilized with $70 \%$ ethanol and $0.1 \% \mathrm{HgCl}_{2}$ solution. Seeds were planted in sterilized pot containing mixture of sterilized sand and clay $(1: 1 \mathrm{w} / \mathrm{w})$ with three replicates. Soil was washed and autoclaved three times at $121^{\circ} \mathrm{C}$ for one hour at three days. Seedlings were

Table 1. Genetic marker in five bacterial strains leading to 10 antibiotics.

\begin{tabular}{|c|c|c|c|c|c|}
\hline \multirow{2}{*}{ Antibiotics } & \multicolumn{5}{|c|}{ Bacterial strains } \\
\hline & H-CP6А-16 & P14A & H-P12B-41 & H-P14A-37 & H-LN7D-18 \\
\hline Chloramphenicol & - & + & - & + & + \\
\hline Streptomycin & + & + & + & + & + \\
\hline Tetracycline & - & + & - & + & - \\
\hline Sulphanilamide & + & + & + & + & + \\
\hline Ampicilin & - & + & - & - & + \\
\hline Kanamycin & - & + & + & + & + \\
\hline Erythromycin & + & + & + & + & + \\
\hline Cephalotaxime & + & - & + & - & - \\
\hline Rifampicine & - & + & + & + & + \\
\hline Gentamycin & - & - & - & - & - \\
\hline
\end{tabular}

+ means resistant, - means sensitive to antibiotics 
Table 2. Di-parental mating between Rhizobium strains isolated from chickpea, pea and lentil.

\begin{tabular}{lllll}
\hline S.N. & Strains for electro-fusion & Relevant genotype of strains & Voltage applied & $\begin{array}{l}\text { Selective } \\
\text { markers }\end{array}$ \\
1 & H-CP6A-16 X P14A (DP-C6-P14) & $\mathrm{Cp}^{\mathrm{r}} \mathrm{Tc}^{\mathrm{s}} \mathrm{Ap}^{\mathrm{s}} \times \mathrm{Cp}^{\mathrm{s}} \mathrm{Tc}^{\mathrm{r}} \mathrm{Ap}^{\mathrm{r}}$ & $2500 \mathrm{~V}$ & $\mathrm{Ap}+\mathrm{Cp}$ \\
2 & $\mathrm{H}-\mathrm{CP} 6 \mathrm{~A}-16$ X H-P14A-37 (DP-C6-HP14) & $\mathrm{Cp}^{\mathrm{r}} \mathrm{Tc}^{\mathrm{s}} \times \mathrm{Cp}^{\mathrm{s}} \mathrm{Tc}^{\mathrm{r}}$ & $1500 \mathrm{~V}$ & $\mathrm{Tc}+\mathrm{Cp}$ \\
3 & H-CP6A-16 X H-LN7D-18 ( DP-C6-HLN) & $\mathrm{Cp}^{\mathrm{r}} \mathrm{Rf}^{\mathrm{s}} \times \mathrm{Cp}^{\mathrm{s}} \mathrm{Rf}^{\mathrm{r}}$ & $2500 \mathrm{~V}$ & $\mathrm{Rf}+\mathrm{Cp}$ \\
4 & H-P12B-41 X H-LN7D-18 (DP-HP12-HLN) & $\mathrm{Cp}^{\mathrm{r}} \mathrm{Ap}^{\mathrm{s}} \times \mathrm{Cp}^{\mathrm{s}} \mathrm{Ap}^{\mathrm{r}}$ & $1000 \mathrm{~V}$ & $\mathrm{Ap}+\mathrm{Cp}$ \\
5 & H-P14A-37 X H-LN7D-18 (DP-HP14-HLN) & $\mathrm{Tc}^{\mathrm{r}} \mathrm{Ap}^{\mathrm{s}} \times \mathrm{Tc}^{\mathrm{s}} \mathrm{Ap}^{\mathrm{r}}$ & $2500 \mathrm{~V}$ & $\mathrm{Ap}+\mathrm{Tc}$ \\
\hline
\end{tabular}

*Concentration of antibiotics in $\mu \mathrm{g} / \mathrm{ml}$

Table 3. Comparative symbiotic infection ability and promiscuity of electro-fusants and their respective parental rhizobia isolates on Pea, Chickpea and Lentil.

\begin{tabular}{|c|c|c|c|c|c|c|c|c|c|c|}
\hline \multirow{2}{*}{ S.N. } & \multirow{2}{*}{ Strains } & \multicolumn{3}{|c|}{ Average no. of nodules per plant } & \multicolumn{3}{|c|}{ Per plant Fresh wt. (gm) } & \multicolumn{3}{|c|}{ Per plant Dry wt. (gm) } \\
\hline & & Pea & Chickpea & Lentil & Pea & Chickpea & Lentil & Pea & Chickpea & Lentil \\
\hline 1 & CP6A & 0.00 & 7.25 & 0.00 & 3.40 & 5.09 & 1.52 & 0.86 & 1.06 & 0.26 \\
\hline 2 & $\mathrm{CP} 7 \mathrm{C}$ & 5.00 & 8.21 & 2.75 & 4.03 & 5.26 & 2.50 & 1.10 & 1.17 & 0.46 \\
\hline 3 & CP11A & 14.40 & 8.75 & 5.00 & 6.22 & 5.99 & 3.47 & 1.46 & 1.28 & 0.58 \\
\hline 4 & $\mathrm{P} 12 \mathrm{~B}$ & 16.71 & 0.00 & 2.30 & 5.81 & 4.13 & 3.32 & 1.29 & 0.82 & 0.53 \\
\hline 5 & P14A & 19.00 & 0.00 & 4.00 & 6.19 & 4.38 & 3.51 & 1.55 & 0.80 & 0.59 \\
\hline 6 & LN7D & 13.80 & 4.37 & 23.50 & 5.32 & 4.58 & 4.07 & 1.26 & 0.92 & 0.68 \\
\hline 7 & DP-C6-P14 & 13.00 & 8.50 & 0.00 & 5.97 & 5.37 & 1.77 & 1.52 & 1.27 & 0.27 \\
\hline 8 & DP-C6-HP14 & 15.75 & 12.40 & 1.50 & 6.51 & 5.24 & 2.31 & 1.58 & 1.18 & 0.27 \\
\hline 9 & DP-C6-HLN & 3.75 & 15.75 & 10.00 & 4.61 & 5.25 & 3.67 & 1.08 & 1.64 & 0.32 \\
\hline 10 & DP-HP12-HLN & 23.00 & 0.75 & 13.00 & 7.35 & 4.36 & 3.50 & 0.51 & 1.11 & 0.41 \\
\hline 11 & DP-HP14-HLN & 31.75 & 0.00 & 18.50 & 7.92 & 3.02 & 4.08 & 2.04 & 0.67 & 0.60 \\
\hline 12 & -ve control & 0.00 & 0.00 & 0.00 & 3.26 & 3.81 & 1.47 & 0.94 & 0.69 & 0.23 \\
\hline
\end{tabular}

inoculated with $4 \mathrm{ml}$ of fully grown parental strains and their transconjugants rhizobial inoculam (about $10^{9}$ cells). After germination in each pot, three plants were maintained. Un-inoculated pots served as negative controls. Plants were examined daily and were replenished with Slogger's N free solution and sterilized distilled water alternatively. Nodulation was observed after 45 days. Plants were uprooted and nodules were washed carefully with tap water and counted on each plant.

Plant biomass: Plant biomass was determined by taking their fresh weight on sensitive weighing balance. For dry weight shoots were kept in oven at $80^{\circ} \mathrm{C}$ for 3 days and weight was taken until it get stabilised. Total nitrogen content of plants was estimated by kjeldahl's steam distillation method.

Symbiotic ratio (SR) analysis: The symbiotic ratio (SR) was used as a measure to discriminate between the nitrogen fixing efficiencies of different rhizobial strains (Charman and Ballard, 2004).

The symbiotic ratio for different isolates/genotypes was calculated as:

$$
\begin{gathered}
\text { Symbiotic ratio } \\
\text { (for shoot biomass) }
\end{gathered}=\frac{\begin{array}{c}
\text { Shoot biomass after inoculation with different } \\
\text { rhizobial isolates/genotypes }
\end{array}}{\text { Shoot biomass of non-inoculated control plants }}
$$

The symbiosis was considered to be ineffective when the symbiotic ratio was $<2$ and effective if the ratio was in the range 2 to $<4$.

\section{RESULTS}

Screening of rhizobial isolates on complex carbohydrate media: All the wild type rhizobial isolates were analysed for their growth behaviour on five different

\begin{tabular}{|c|c|c|c|c|}
\hline \multirow{2}{*}{ S.N. } & \multirow{2}{*}{ Strains } & \multicolumn{3}{|c|}{$\mathrm{Ngm} / \mathbf{1 0 0 g m}$} \\
\hline & & Shoot of chickpea & Shoot of pea & Shoot of lentil \\
\hline 1 & CP6A & 3.13 & 2.06 & 1.64 \\
\hline 2 & CP7C & 3.40 & 2.29 & 1.85 \\
\hline 3 & CP11A & 3.20 & 3.19 & 2.25 \\
\hline 4 & P12B & 1.87 & 3.71 & 2.03 \\
\hline 5 & P14A & 2.24 & 3.89 & 2.38 \\
\hline 6 & LN7D & 2.44 & 3.54 & 3.90 \\
\hline 7 & DP-C6-P14 & 3.35 & 2.75 & 2.98 \\
\hline 8 & DP-C6-HP14 & 3.56 & 2.98 & 3.00 \\
\hline 9 & DP-C6-HLN & 3.71 & 1.76 & 3.67 \\
\hline 10 & DP-HP12-HLN & 1.84 & 3.02 & 2.89 \\
\hline 11 & DP-HP14-HLN & 1.90 & 3.92 & 4.03 \\
\hline 12 & -ve control & 1.67 & 1.83 & 1.99 \\
\hline
\end{tabular}
media containing diverse carbon source. Colony size

Table 4. Total shoot nitrogen of Chickpea, Pea and Lentil estimated by Kjeldahl's method. 


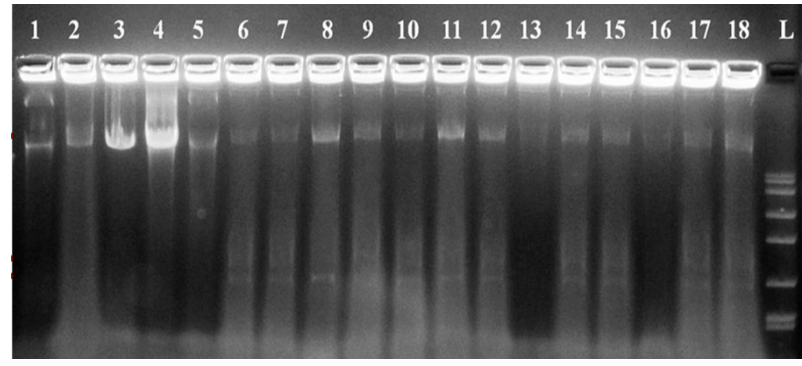

Fig. 1. Plasmid patterns of selected bacterial isolates using in gel lysis method.

of each strain was measured, most of the bacteria grew very poorly and increment of growth was not observed even after 8 days. Twenty four isolates showing better growth on $\mathrm{CMC}$ and pectin medium were selected from all the two hundred ninety five rhizobial isolates. They grew well on media containing $\mathrm{CMC}$, since it allowed apparently good cellulase production by these bacteria. It was observed that rhizobial isolates having higher cellulose and pectin utilizing ability found to be greater establishment of symbiotic interaction (Aggarwal et al., 2000). The optimal incubation time for the highest growth on CMC was determined by testing bacterial species. Two days incubation provided only faintly visible colonies and the maximal colony diameter was achieved between 4 and 5 days. Colony diameters did not increase substantially after 5 days.

Electro-fusion among diverse strains for obtaining cross infective rhizobia: Di-parental mating between selected Rhizobium leguminosarum and Mesorhizobium ciceri were carried out through electro-fusions. Contrasting antibiotic resistance profile used as selectable marker to obtain the electro-fusant cells (Table 2). Three colonies from each combination were picked and their antibiotic resistance profile was confirmed by screening for growth at higher antibiotic concentrations. It was found that electro-fusants of cross H-P12B-41 Vs. H-LN7D-18 were growing even at higher concentration of ampicillin and cephalotaxim $(50 \mu \mathrm{g} / \mathrm{ml})$ which were selectable marker for these two combinations. Five fusants, DP-C6-P14, DP-C6-HP14, DP-C6-HLN, DP-HP12-HLN and DP-HP14-HLN which had their resistance pattern confirmed were used in plant infection test to analyse their symbiotic infection behaviour.

Analysis of intrinsic plasmid patterns: Plasmid pattern of the bacterial isolates were analysed using in gel lysis method. Different plasmid profiles were observed in the selected bacterial isolates (Fig. 1). Three plasmids were observed in H-CP6A-16, P14A, H-P12B-41 and H-P14A-37 strains among which mega -plasmid was same size while two smaller plasmids obtained from these strains were comparable in size. Two plasmids were observed in strain H-LN7D-18. It was observed that four transconjugants have all the three plasmids of same size while transconjugant DP-HP12-HLN lost two small plasmids and only one plasmid was observed. This indicated that the small plasmid had been lost after electro-poration. The number of different plasmids present in rhizobia is variable both within a given species and among species.

Evaluations of symbiotic infection behaviour and cross infectivity: Symbiotic infection behaviour and cross infectivity of transconjugants and their mid parent rhizobial strains were evaluated on chickpea, pea and lentil plants under sterile conditions. All the three legume hosts were inoculated through transconjugants and their respective mid parental strains to check promiscuous infection behaviour of particular rhizobial culture. Nodulation ability of the strains was analysed by harvesting the plants after 45 days and it was found to be characteristically different. The nodulation ability of transconjugants was high as compaired to their respective parental strains. All the un-inoculated control plants were free from nodules. Thus, it was concluded that growth conditions were appropriate for nodulation and that rhizobial contamination was not responsible for the results obtained. Fresh weight and number of nodules in all plants were counted after harvesting as presented against each of the strain and plant in (Table 3). The plants inoculated with the transconjugants strains exhibited more than 95\% elongated pink nodules. The highest nodule number 31 was obtained on the roots of pea when it was infected with transconjucant DP-HP14-HLN. In case of chickpea 15 number of nodules per plant with transconjucant DP-C6-HLN while lentil showed 18 highest number of nodule with transconjucant DP-HP14-HLN. The nodules numbers appeared due to modified strains were increase around 50 to $122 \%$ of their respective parents. The greater number of active nodules expected to contribute to more nitrogen fixation which increases plant growth under nitrogen deficient conditions. Plant biomass in terms of shoot

Table 5. Comparative total shoot nitrogen contents of host and non-host legume.

\begin{tabular}{lcccccc}
\hline \multirow{2}{*}{ Origin of strain } & \multicolumn{2}{c}{ On Pea } & \multicolumn{2}{c}{ On Chickpea } & \multicolumn{2}{c}{ On Lentil } \\
\cline { 2 - 6 } & Avg. $\mathbf{~}$ & \% increase N & Avg. $\mathbf{~}$ & \% increase N & Avg. N & \% increase N \\
\hline Chickpea & 2.51 & 26.13 & 3.24 & 24.13 & 1.9 & 2.68 \\
Pea & 3.80 & 41.26 & 2.34 & 25.13 & 2.20 & 29.41 \\
Lentil & 3.54 & 95.58 & 2.44 & 40.22 & 3.90 & 34.48 \\
Chickpea x pea & 2.86 & 22.22 & 3.45 & 54.01 & 2.99 & 67.97 \\
Pea x lentil & 3.47 & 54.22 & 1.87 & 3.88 & 3.46 & 50.43 \\
Lentil x chickpea & 1.76 & NA & 3.71 & 70.96 & 3.67 & 54.20 \\
\hline
\end{tabular}



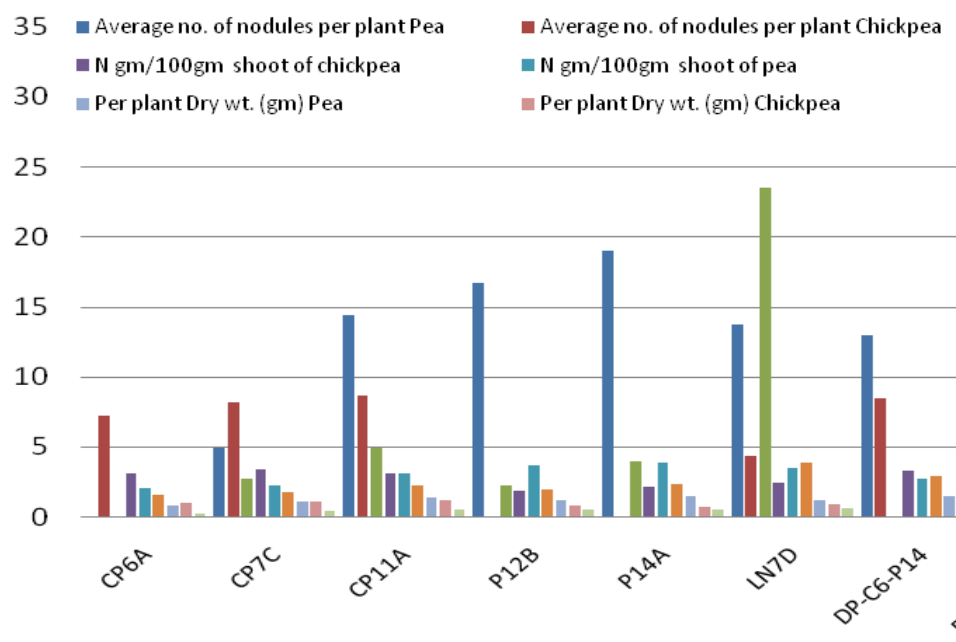

Fig. 2. Comparisons of nodule number, dry weight and nitrogen fixation by different strains on diverse host.

fresh and dry weights was determined and they were compared among the diverse test combinations (Fig. 2). Most of the plants inoculated with wild type culture lose their weight after drying while dry weight was found to be highest in those plants which were infected with transconjugants strains revealing higher nitrogen content.

Estimation of total shoot nitrogen content: Total shoot nitrogen content of all the plants was estimated through Kjeldahl's method. The amount of nitrogen was found directly proportional to the number of nodules. The amount of nitrogen fixed in chickpea was highest (3.71gm) by transconjugants DP-C6-HLN followed by DP-C6-HP14 (3.56gm). Transconjugants DP-HP14-HLN fixed the highest amount of nitrogen (3.92gm) in pea and 4.06gm in lentil plant (Table 4). Here the significant increase in shoot $\mathrm{N}$ content was also observed.

\section{DISCUSSION}

Efforts towards creating rhizobia having broad host range were carried out by fusion of Rhizobium leguminosarum and Mesorhizobium ciceri strains through electro-poration. Twenty four bacterial strains were genetically marked using ten antibiotics. The results showed that tetracycline, cephalotaxime, ampicillin and rifampicine were effective to evaluate variability of bacterial (Table 1) strains because only the hybrid strains grown on the media having the combination of antibiotics. Earlier intrinsic antibiotic resistance pattern has been utilized to evaluate variability in rhizobia (Mishra et al., 1975; Jayachandran and Balasubramaniam, 1978; Vashishat and Yadav, 1985a and Eaglesham, 1987, Kawaharada et al., 2015,). As noted in previous studies (Rasool, 2003 and Cresti et al., 2002), there was a correlation between the antibiotic resistance phenotype and the genotype. In this study it was observed that there are variations between different bacterial strains in the antibiotic resistance. The best strains isolated from diverse legumes having con- trast antibiotic resistance were selected for electroporation (Table 2). The di-parental trans-conjugants strains were developed to extend their symbiosis to the non-hosts. Similarly Garg et al. (1999) successfully carried out electro-transformation of Rhizobium leguminosarum with a $15 \mathrm{~kb}$ plasmid, pMP154, by electroporation. They found that electro-poration is a novel approach for introduction of foreign DNA into bacterial species. We observed different plasmids profile after electro-poration that indicates genetic rearrangements in transconjugants. The number plasmids may even variable within a given species and among the species of rhizobia (Young et al., 2006). Transconjucant DP-HP12-HLN lost two small plasmids and only one plasmid was observed. The previous studies indicate that plasmid transfer or plasmid loss may increase nodulation or nitrogen fixation in Rhizobia strains (DeJonj et al., 1982, Pankhurst et al., 1986). Previous studies show that plasmid can be transferred from different genomic backgrounds that can extend nodulation hostrange (Galardini et al., 2011, Gonzalo et al., 2011). These observations taken together indicate that these isolates behave like parasitic organisms rather than bona-fide legume symbionts (Kundu and Dudeja, 2008, Oldroyd et al., 2011 and Nadwani and Dudeja, 2013). Thus the relative permissiveness of the hosts may leads to the formation of ineffective nodules and not guarantee effectiveness in $\mathrm{N}_{2}$-fixation (Andrade et al., 2002).

The symbiotic infection and promiscuous behaviour of electro-fused strains and their mid parents was analyzed under sterile condition. All the transconjugants obtained from di-parantal mating were successfully cross nodulate the legumes other than their native host and the number of nodules were increase from 50 to $122 \%$ as compared to their parental strains. Transconjugant DP-HP14-HLN was found to be the most effective one for pea and lentil but it is not so effective for chickpea. It has also the highest efficacy in terms of symbiotic ratio. All transconjugents except 
DP-C6-P14 appeared significant increase in nodule number above their mid-parents. Whereas, All Transconjugants (except DP-C6-HLN) appeared significant increase in shoot fresh weight per plant above their mid-parents (Table 3). Nitrogen yield of the plants was also increased up to $67 \%$, when inoculated with the transconjugants rhizobial strains as compared with the un-inoculated controls. These are in agreement with Martinez et al. (1987), who found that genetic transfer between Rhizobium species has led to increase nodulation and nodule fresh and dry weight in legumes along with increase the growth and development of host plant. Similarly Truchet et al. (1991) illustrated that trans-conjugants resulted from di-parental mating showed significant increase above the mid-parents in nodule number and dry weight of shoot. Musiyiwa et al. (2005) also reported a high effectiveness and nodule occupancy of genetically modified strains.

The present experiments greatly expand previous observations of Sai"d et al. (1998) they observed that conjugation of plasmid into Rhizobium fredii extends the host range of the recipient to the non-hosts. Steven and William (1999) mobilized the symbiotic plasmid (pNGR234a) of Rhizobium sp. NGR234 into heterologous rhizobia and observed trans-conjugant's extension of host range. Similar reports were found earlier in relative activity of different rhizobia such as Rhizobium phaseoli, Rhizobium trifolii BAL Rhizobium trifolii BART-A (Giraud et al., 2007, Yoshitake et al. (2010) and Nascimento et al., 2012). The present study provides evidences towards variability and dynamics in relation to the host plant. The developed strains have the capability to infect the non-host plants. These promiscuous strains are highly efficient for nitrogen fixation and nodulate non host plants in the same manner as it does with the native host.

\section{Conclusion}

The results of the present study showed that the majority of the strains were highly promiscuous and effective with the symbiotic partners. Application of such effective rhizobia strains as biofertilizers to improve legume production is an important approach in sustainable agriculture. The presence of an effective rhizobial population may obviate the need for inoculation, with which the rhizobia were able to form efficient symbiotic associations in all the soils. Therefore, to avoid the problem of competitiveness, the use of promiscuous rhizobial inoculation could be another alternative.

\section{REFERENCES}

Aggarwal, M., Sikka, V.K. and Vashishat, R.K. (2000). Symbiotic properties of Rhizobium trifolii mutants altered for cell wall degradative ability. Trop. Ag., 77: 109-111.

Andrade, F.H., Calviño, P.A., Cirilo, A. and Barbieri, P.A. (2002). Yield responses to narrow rows depend on increased radiation interception. Agronomy. J., 94:975-980

Carden, D.E. and Felle, H.H. (2003). The mode of action of cell wall degrading enzymes and their interference with nod factor signalling in Medicago sativa root hairs. Planta., 216(6): 993-1002

Charman, N. and Ballard, R.A. (2004). Burr medic (Medicago polymorpha L.) selections for improved $\mathrm{N}_{2}$ fixation with naturalized soil rhizobia. Soil Biol. Biochem., 36:1331-1337

Chassy, B.M., Mercenier, A. and Flickinger, J. (1988). Transformation of bacteria by electroporation. Trends Biotechnol., 6:303-309

Chitchanok, A., Rattasaritt, P., Suthatip, S., Suphaporn, P., Nattayana, P. and Yanee, T. (2011). Improvement of vitamin B6 production from Rhizobium sp. 6-1C1 by random mutation. KKU Res J., 16(8): 911-918

Cresti, S., Lattanzi, M., Zanchi, A., Montagnani, F., Pollini, S., Cellesi, C. and Rossolini, G.M. (2002). Resistance determinants and clonal diversity in group A streptococci collected during a period of increasing macrolide resistance. Antimicrob Agents Chemother, 46:18161822

De Jonj, T.M., Brewin, N.J., Johnston, A.W. B. and Phillips, D.A. (1982). Improvement of symbiotic properties in Rhizobium leguminosarum by plasmid transfer. J. Gen. Microbiol., 128:1829-1838.

Dixon, R. and Daniel, K. (2004) Genetic regulation of biological nitrogen fixation. Microbiol. 2: 621-631

Dunican, L.K. and Cannon, F.C. (1971). The genetic control of symbiotic properties in Rhizobium: evidence for plasmid control. Plant Soil (Spec. vol.):73-79

Eaglesham, A.R.J. (1987). The use of intrinsic antibiotic resistance for Rhizobium study. In: G. H. Elkan (ed.) symbiotic nitrogen fixation technology. Marcel Dekka, Inc., New York. 185-204

Eckhardt, T. (1978). A rapid method for the identification of plasmid deoxyribonucleic acid in bacteria. Plasmid 1: 584-588

Esperanza, Martinez-Romero and Monica, R. (1990). Increased Bean (Phaseolus vulgaris L.) nodulation competitiveness of genetically modified Rhizobium strains. Appli. and Environ. Microbiol., 56(8):23842388

Galardini, M., Mengoni, A., Brilli, M., Pini, F., Fioravanti, A. and Lucas, S. (2011). Exploring the symbiotic pangenome of the nitrogen-fixing bacterium Sinorhizobium meliloti. BMC Genomics, 12: 235

Garg, B., Dogra, R.C. and Sharma, P.K. (1999). High efficiency transformation of Rhizobium leguminosarum by electroporation. Appl. Environ. Microbiol., 65(6): 2802-2804

Giraud, E., Moulin, L., Vallenet, D., Barbe, V., Cytryn, E. and Avarre, J.C. (2007). Legumes symbioses: absence of nod genes in photosynthetic bradyrhizobia. Science, 316:1307-12

Gonzalo, T., Tejerizoa, M.F., Del, P., Walter, D., Mauricio, L., María, Á.G., Carla, M., María, E.S., Ileana, S., Daniel, W., Rafael, S., Stefan, W., Andreas, S., Antonio, L. and Mariano, P. (2011). First genomic analysis of the broad-host-range Rhizobium sp. LPU83 strain, a member of the low-genetic diversity Oregon-like Rhizobium sp. Group. J. of Biotechno., 155: 3-10

Hashem, F.D., Swelim, D.M., Kuykendell, L.D., Mohamed, 
A.I., Abdel-Wahab S.M. and Hegazi, N.I. (1998). Identification and characterization of salt tolerant Leuceana nodulation Rhizobium strains. Biol. Fertil. Soil, 27:35341

Jayachandran, S. and Balasubramaniam, A. (1978). Differences in the polysaccharides produced by $\mathrm{Cam}^{\mathrm{r}}$ and $\mathrm{St}^{\mathrm{r}}$ mutants of Rhizobium sp. Indian J. Microbiol., 18:76-79

Jaynes, D.B., Colvin, T.S., Karlen, D.L., Cambardella, C.A. and Meek, D.W. (2001). Nitrate losses in subsurface drainage as affected by nitrogen fertilizer rate. J. Environ., 30:1305-1314

Kawaharada, Y., Kelly, S., Nielsen, M.W., Hjuler, C.T., Gysel, K., Muszynski, A., Carlson, R.W., Thygesen, M.B., Sandal, N., Asmussen, M.H., Vinther, M., Andersen, S.U., Krusell, L., Thirup, S., Jensen, K.J., Ronson, C.W., Blaise, M., Radutoiu, S. and Stougaard, J. (2015). Receptor-mediated exopolysaccharide perception controls bacterial infection. Nature, 523: $308-312$

Kundu, S. and Dudeja, S.S. (2008). Molecular diversity, predominance and effectiveness of mungbean rhizobia. Indian J. Microbiol., 48: 432-439

Li, Q. Q., Wang, E. T., Zhang, Y. Z., Zhang, Y. M., Tian, C. F., Sui, X. H., Chen, W. F. and Chen, W. X. (2011). Diversity and biogeography of rhizobia isolated from root nodules of Glycine max grown in Hebei Province, China. Microb. Ecol., 61: 917-931

Martinez, E., R. Palacios and Sanchez, F. (1987). Nitrogen fixing nodules induced by Agrobacterium harboring Rhizobium phaseoli plasmids. J. Bacteriol., 169:28282834

Martinez, R.E. and Caballero, M.J. (1996). Rhizobium phylogenies and bacterial genetic diversity. Crit. Rev. Plant Sci., 15:113-140

Mishra, A.K., Roy, P. and Das, S.K. (1975). Occurance of streptomycin resistant and dependant mutations in Rhizobium lupin under the influence of nitrous acid. Curr. Sci., 44: 267-269

Mosier, A.R., Wassmann, R., Verchot, L., King, J.Y. and Palm, C. (2004). Methane and nitrogen oxide fluxes in tropical agricultural soils: Sources, sinks and mechanisms. Environ. Develop. and Sustain., 6:11-49

Musiyiwa, K., Mpepereki, S. and Giller, K.E. (2005b) Symbiotic effectiveness and host ranges of indigenous soybean varieties in Zimbabwean soils, Soil Biol. Biochem., 37: 1169-1176

Nadwani, R. and Dudeja, S.S. (2013) Functional diversity of native mesorhizobial genotypes nodulating chickpea in Indian soils of Haryana State. Acta Agronomica Hungarica, 61(3): 207-217

Nascimento, F., Brigido, C., Alho, L., Glick, B.R. and Oliveira, S. (2012). Enhanced chickpea growth promotion ability of a Mesorhizobium strain expressing an exogenous ACC deaminase gene. Plant Soil., 353:221-30

Oldroyd, G.E.D., Murray, J.D., Poole, P.S. and Downie, J.A. (2011). The rules of engagement in the legumerhizobial Symbiosis. Annu. Rev. Genet., 45:119-144

Pankhurst, C.E., Macdonald, P.E. and Reeves, J.M. (1986).
Enhanced nitrogen fixation and competitiveness for nodulation of Lotus pedunculatus by a plasmid-cured derivative of Rhizobium loti. J. Gen. Microbiol., 132: 2321-2328

Rasool, S.A., Ahmad, A., Khan, S. and Wahab, A. (2003). Plasmid Borne Antibiotic Resistance Factors among Indigenous Klebsiella Pak. J. Bot., 35(2): 243-248

Rosenblueth, M., Hynes, M.F. and Martinez-Romero, E. (1998). Rhizobium tropici teu genes involved in specific uptake of Phaseolus vulgaris bean-exudate compounds. Mol. Gen. Genet., 258:587-598

Saı"d, J., Biserka, R., Moez, H., Philippe, K., Ulrich, B., Danielle, Prome., Jean, C.P. and William, J.B. (1998). nolO and noeI (HsnIII) of Rhizobium sp. NGR234 are involved in 3-O-carbamoylation and 2-O-methylation of Nod factors. The J. of Biolo. Chemi., 273(20):1204712055

Shiferaw, B., Bantilan, M.C.S. and Serraj, R. (2004). Harnessing the potential of BNF for Poor Farmers: Technological Policy and institutional constraints and research need. Symbiotic Nitrogen Fixation; prospects for enhanced application in tropical agriculture. (ed.): R. Serraj. Oxford and IBH publishing Co. Pvt. Ltd. New Delhi. pp.3.

Steven, G. and William, J.B. (1999). Rhizobium sp. Strain NGR234 and $R$. fredii USDA257 Share exceptionally broad, nested host ranges. The Ameri. Phytopatholo. Socie., 12(4): 293-318

Truchet, G., Roche, P., Lerouge, P., Vasse, J., Camut S., de Billy, F., Prome, J.C. and Denarie, J. (1991). Sulphated lipo-oligosacchride signal of Rhizobium meliloti root nodule organogenesis in alfalfa. Nature, 351: 670-673

Vashishat, R.K., Yadav, A.S. and Chaudhary, K. (1985b). Production of hydrolytic enzymes in non-nodulating strains of Rhizobium trifolii. Haryana Agric. Univ. J. Res., 15:403-405

Vincent, J.M. (1970). A manual for the practical study of the root nodule bacteria. Blackwell Scientific Publications, Oxford. pp.7-9

Vlassak, K.M. and Vanderleyden, J. (1997). Factors influencing nodule occupancy by inoculant rhizobia. Crit. Rev. Plant Sci., 16:163-229

Yoshitake, O., Yoshinobu, N., Takuji, O., Hidetoshi, O., Nobutoshi, I., Isao, Y., Naoki, M., Min, W. and Takuji, O. (2010). Enhancement of the nitrogen fixation efficiency of genetically-engineered Rhizobium with high catalase activity. J. of Biosci. and Bioengin., 110(4):397-402

Young, J.P.W. and Johnston, A.W.B. (1989). The evolution of specificity in the legume-Rhizobium symbiosis. Trends Ecol. Evol., 4:331-349

Young, J.P., Crossman, L., Johnston, A., Thomson, N., Ghazoui, Z. and Hull, K. (2006). The genome of Rhizobium leguminosarum has recognizable core and accessory components. Genome Biol., 7: R34.

Zhao, M., Faith, T., Ann, H., Ramakrishna, R.N. and Steven, W.R. (2005). Improvements of the MODIS terrestrial gross and net primary production global data set. Rem. Sens. of Envir., 95:164-176 